\title{
De Julios-Campuzano, A., Constitucionalismo. Un modelo jurídico para la sociedad global, Pamplona: Aranzadi, 2019.
}

\author{
Itamar de Ávila Ramos \\ Universidad de Burgos
}

Fecha de recepción 28/05/2020 | De publicación: 28/12/2020

En 1945, la Segunda Guerra Mundial llegó a su fin, caracterizada como una de las ocasiones en que ocurrieron las mayores violaciones de los derechos humanos. Desde entonces, bajo el punto de vista político-jurídico-social, tenemos el llamado constitucionalismo contemporáneo, con el objetivo de promover la limitación del poder y la observancia de los derechos, de una manera más amplia y justa.

Hoy, setenta y cinco años después, en mayo de 2020, en un escenario mundial globalizado, lo que se puede ver sobre el constitucionalismo de la segunda posguerra, desde la perspectiva del cumplimiento de los objetivos/compromisos antes mencionados, es la existencia de una crisis de credibilidad, marcada, por un lado, por la existencia de múltiples instancias que producen leyes y, por otra, por las preguntas sobre cuáles deberían ser las concepciones actuales adoptadas/practicadas con respecto a los conceptos de soberanía y democracia de los Estados.

En medio de todos los problemas sociales, legales y políticos actuales que enfrentan los Estados, el libro "Constitucionalismo. Un modelo jurídico para la sociedad global”, surge en el seno del proyecto "Fundamentos teóricos del neoconstitucionalismo", financiado por el Ministerio de Economía y Competitividad, bajo la coordinación de Alfonso De Julios Campuzano y de José María Ribas Alba, buscando presentar análisis y propuestas para mejorar el constitucionalismo contemporáneo.

La obra recoge las contribuciones científicas de dieciocho investigadores de ámbito nacional e internacional. Debido a la relevancia del tema que presenta, constituye una lectura indispensable para los investigadores de ciencias sociales, y gana aún más atractivo cuando su lanzamiento coincide con la aparición de Covid-19, una nueva enfermedad, con alta transmisibilidad entre los seres humanos y sin evidencia científica de la existencia de tratamientos médicos y/o vacunas eficientes. 
Esta enfermedad, que ha ignorado las fronteras territoriales, ha promovido consecuencias impensables para su salud, economías y sistemas de trabajo, planteando preguntas sobre temas como la soberanía, la democracia, la integración de bloques regionales de países, la solidaridad y la globalización como los conocemos hoy.

La obra se estructura en cuatro partes: Dimensiones históricas; Dimensiones regionales y supranacionales; Constitucionalismo, derechos, identidades y, al final, Los desafíos actuales de la democracia constitucional, todos unidos por el hilo común de entender el constitucionalismo contemporáneo en el mundo globalizado. La preocupación por enfrentar crisis históricas relacionadas con los temas de soberanía y democracia, así como los estudios sobre cuáles serían los posibles caminos actuales para la realización de los ideales y objetivos del Estado Constitucional, emergen como aspectos dignos de elogio del trabajo.

Observando la secuencia de los títulos de las partes del libro, es posible inferir, desde el principio, la existencia de una dimensión prospectiva, que se percibe en la preocupación de sus organizadores para que las contribuciones de los participantes tengan sus ojos puestos en el futuro de los temas investigados, sin apartarse de la apreciación y la revisión crítica de sus enfoques en el pasado.

Se puede encontrar un pensamiento similar en el trabajo de Dworkin, quien, al concebir la metáfora de la novela en cadena, enfatiza el deseo necesario de que cada autor de un nuevo capítulo de una novela considere su importante responsabilidad de continuidad de lo que ya se ha escrito, teniendo cuidado de tratarlo. Es un trabajo conjunto, en el que pretenden promover la mejor calidad posible, bajo el enfoque del proceso interpretativo.

Entre sus primeras páginas, encontramos artículos que buscan resaltar aspectos relacionados con las dimensiones históricas del constitucionalismo. Justo en su pórtico, una excelente reflexión del profesor de la Universidad de Sevilla, José María Ribas Alba, sobre el constitucionalismo romano, especialmente en relación con la participación ciudadana, que había existido desde la monarquía, evidenciada por las asambleas políticas de la curia y que pasó por alto otras formas a través de los períodos de la república y el imperio. Con este fin, realiza un análisis crítico de la obra de Marco Pani, "Il costituzionalismo di Roma antica", añadiendo sus consideraciones sobre la necesaria valoración de la percepción del principio democrático en las instituciones políticas romanas. 
El profesor de la Universidad de Évora, Silverio da Rocha-Cunha, en el tercer artículo de la primera parte del libro - Dimensiones históricas - dirige su atención al pensamiento del filósofo Franz Neumann, uno de los miembros de renombre de la Escuela de Frankfurt. La estructuración realizada por el profesor portugués presenta, a través de seis reflexiones, los aspectos más relevantes de la creación, las características sorprendentes, los objetivos, el espectro multifacético de los temas estudiados, las vicisitudes enfrentadas y la influencia ejercida hasta hoy por los estudios desarrollados por miembros del Instituto para la Investigación Social.

Iniciado durante la República de Weimar con el objetivo de revisar los paradigmas hasta ahora instituidos y constituidos por pensadores generacionales que han influido en los estudios occidentales desde entonces hasta hoy, llega la Critical Theory, en parte a partir de los estudios desarrollados por Neumann, un demócrata radical, interpretado por Silverio da Rocha-Cunha. A pesar de la aparente desconexión de los ejes centrales de los temas que podrían provenir de una lectura expedita de las partes que componen el texto, al final el artículo revela la importancia de comprender los estudios desarrollados por Neumann con respecto a los conceptos de Estado democrático y soberanía, teniendo a través del hilo entrelazado, la perspectiva de la soberanía democrática y sus posibilidades de percepción en el mundo cada vez más globalizado de hoy.

Enrique César Pérez-Luño Robledo, en el segundo artículo de la segunda parte del trabajo Dimensiones Regionales y Supranacionales -, titulado "La cooperación judicial transnacional y la garantía de los derechos humanos, a partir del Reglamento 2017/1939 de la Unión Europea”, realiza un análisis de las posibles relaciones entre la recién creada Autoridad Fiscal Europea y la defensa de sus derechos fundamentales. A través de la formulación de cinco preguntas sobre el modelo del ministerio público europeo, explica que en el ámbito de la Unión Europea hay tres modelos diferentes de inspección: el francés, el italiano y el inglés. El norte de las reflexiones del artículo en cuestión se refiere a la importante priorización de los análisis en cuanto a las grandes posibilidades de acciones de la Auditoría Europea, considerando que es evidente que su constitución fue guiada por un sesgo flagrante de enfoque directo en la protección de los intereses económicos, y que para el resto de los derechos de la garantía solo tendrían un carácter indirecto o reflexivo.

Con el estudio de la profesora Nuria Belloso Martín, "La articulación del diálogo judicial entre tribunales: una lectura desde la filosofía jurídica y la hermenéutica" comienza la Tercera Parte del libro -Constitucionalismo, Derechos, Identidades-. Superando la dimensión internacionalista y procesalista 
bajo las que se ha tratado habitualmente esta cuestión, la autora se ha centrado en una perspectiva filosófico-jurídica para analizar los presupuestos iusfilosóficos necesarios para articular un verdadero diálogo judicial entre tribunales, superando las dificultades que radican en el propio concepto de “diálogo" y prestando atención a las transformaciones que se producen en los sistemas jurídicos actuales (reformulación del concepto y fundamento del Derecho, soberanía nacional, coexistencia entre procesos de globalización y refuerzo de sistemas regionales, entre otros). Además de clarificar qué se entiende por tal "diálogo" judicial, se cuestiona el por qué y el para qué de tal diálogo, es decir, la causa y la finalidad. No se trata de una simple moda ni de un efecto más de la globalización, sino de una imperiosa necesidad para una mejor protección de los derechos humanos en el ámbito internacional. Finalmente, se analiza el cómo se lleva a cabo el diálogo judicial, presentando la autora un original y agudo análisis del diálogo judicial como diálogo hermenéutico, a partir de unos presupuestos teóricos y éticos. Es reseñable que la Dra. Belloso Martín no hace una defensa cerrada de los diálogos interjudiciales, como si todos tuvieran que ser consensuales y desembocar en acuerdos. Por el contrario, admite que los "diálogos críticos", también pueden resultar en ocasiones más fructíferos en orden a ayudar a buscar mejores alternativas para la protección de los derechos humanos.

Son, sin duda, destacadas las aportaciones de Teresa Freixes sobre el constitucionalismo multinivel y su implementación en la Unión Europea y la reflexión que Roberto Miccú realiza en torno al Mecanismo Europeo de Estabilidad como nuevo paradigma económico-constitucional.

Los profesores brasileños José Luiz Bolzan de Morais y Edilene Lobo, presentan sus reflexiones, en la cuarta parte del libro - Retos reales de la democracia constitucional - abordando un tema muy reciente, como es el "Las nuevas tecnologías y el modelo de comunicación actual en las opciones brasileñas de 2018 ". A partir de una valoración de los puntos positivos y negativos que pueden surgir del uso de las tecnologías de comunicación digital, los autores presentan propuestas de mejora para aprovechar las nuevas tecnologías para, bajo la perspectiva electoral, fortalecer los derechos humanos y la democracia.

En esta última parte del libro, en la que se abordan algunos de los principales desafíos que acechan a la democracia constitucional, ocupa un lugar destacado la rigurosa reflexión sobre el populismo y su incidencia sobre los sistemas constitucionales contemporáneos. A ello encamina sus esfuerzos el profesor Delgado del Rincón que, desde la óptica constitucional, nos ofrece un interesante análisis de este fenómeno y ofrece un elenco de medidas orientadas a evitar su expansión y a mejorar la calidad 
democrática. Esta aportación se complementa con la aportación con la que concluye la obra, en la que Alfonso de Julios-Campuzano nos ofrece a una sugestiva aproximación a la nueva oleada populista que afecta a nuestras democracias y cuya sombra se cierne sobre el constitucionalismo y que puede debilitar nuestras instituciones y hace que la democracia se tambalee, aspecto en el que parecen resonar algunas recientes reflexiones que atisban en el populismo un desafío para el constitucionalismo.

En conclusión, en esta obra, se pueden señalar, entre sus numerosos aspectos positivos, la existencia de un enfoque jurídico, político, histórico y social del constitucionalismo, presentado a través de un diálogo lógico y coherente entre sus partes y entre sus capítulos, demostrando un compromiso apreciable en la realización del análisis de los temas de la manera más amplia posible.

Otro aspecto que es notable en este libro es el hecho de que todos sus capítulos se caracterizan claramente por el análisis crítico de los temas tratados, así como por la externalización de propuestas para la mejora del constitucionalismo contemporáneo, que cumplen con creces las expectativas de la parte llamada "Desafíos actuales de la Democracia Constitucional".

Por otro lado, creo que al menos dos puntos merecen un análisis por la coordinación del trabajo con vistas a una segunda edición del mismo, si fuera el caso. La primera es que, considerando el hecho de que el constitucionalismo ha sido muy influenciado por las tradiciones francesas y norteamericanas, las contribuciones de autores de estos países, así como de otros países, en un mundo tan globalizado, ciertamente enriquecerán significativamente los debates.

La desglobalización, el fortalecimiento de los estados nacionales, la regionalización, todo sumado a los estudios de los impactos jurídicos, políticos y sociales promovidos en los Estados con el advenimiento de la pandemia de Covid-19, desde la perspectiva del constitucionalismo contemporáneo, constituyen cuestionamientos actuales que permitirán apreciar aún más los valiosos estudios contenidos en la obra.

Lo que tenemos, al final, es un compendio de trabajos de gran importancia, para las ciencias sociales, de lectura obligatoria, para todos aquellos, investigadores o no, que quieran vivir en una sociedad más libre, más justa, democrática y solidaria. Y, en definitiva, de todos cuantos ven en el constitucionalismo contemporáneo un modelo, sin duda perfectible pero imprescindible para esquivar los desafíos que afronta la humanidad en estos primeros compases de una época de incertidumbres. 